\title{
A Study on the Space Hierarchy According to the Plan Composition in Outpatient Department of Geriatrics Hospitals
}

\author{
Heangwoo Lee, Janghoo Seo and Yongseong Kim \\ The Graduate School of Techno Design, Kookmin University, Jeongneung-dong, \\ Seongbuk-gu, Seoul, 136-702, Korea \\ moonup2001@nate.com.seojh@kookmin.ac.kr.yongkim@kookmin.ac.kr
}

\begin{abstract}
The number of facilities for the elderly is increasing rapidly due to recent rapid increases in the aging population, but relevant qualitative studies have been carried out insufficiently. especially, the number of geriatric hospitals is rapidly increasing as a solution for medical problems of the elderly, but qualitative studies regarding spatial hierarchy and cognition have been carried out insufficiently. Therefore, the purpose of this study is to establish preliminary data for the design of geriatric hospitals through the quantitative hierarchical analysis of plane structure according to the floor plan composition of outpatient departments in geriatric hospitals. In this study, J-graph and space syntax were utilized for quantitative analysis of outpatient departments in geriatric hospitals, and the analysis target was limited to hospitals for the elderly located in Korea, where there was a rapid increase in aging population recently. The analysis results are as follows. 1) The spatial depth of outpatient departments in geriatric hospitals is between 5 and 7 , showing the average spatial depth of 6.5, with the ring type spatial structure shows a higher depth than the tree type spatial structure. 2) Due to the spatial hierarchy of outpatient department, the space for treatment is located in the deepest area, and this may be improper to the elderly with deteriorated physical and cognitive abilities. 3) The outpatient department in geriatric hospitals in tree type shows high connectivity and integration which correspond to the moving line of patients, so it is an appropriate structure to secure accessibility and cognition of outpatient departments easily. 4) The outpatient department in geriatric hospitals in ring type shows a low integration of convex which corresponds to the moving line of patients so that it is not appropriate for spatial cognition. On the other hand, it shows high spatial cognition of common use space so that it is appropriate for social availability. 5) The outpatient department in tree type structure in selected hospitals for the elderly shows the average intelligibility of $35.8 \%$, which is higher in comparison to the outpatient department in ring type structure, so it is appropriate to design the moving line of patients in outpatient departments in geriatric hospitals following the tree structure which has clear spatial hierarchy.
\end{abstract}

Keywords: Geriatrics Hospital, Outpatient Department, J-Graph, Space syntax

\section{Introduction}

\subsection{Background and Purpose of Study}

Extension of average human life is causing fast transformation into the aged society, which leads to the issues of residence, leisure, in-house welfare facility, and healthcare for senior citizens. Efforts to find the solution for healthcare issues have been focused on quantitative increase of senior care facilities to cope with the increase of the senior population, and more qualitative researches on such facilities have yet to be made [1,2]. Especially while the outpatient department of senior care hospitals has similar structures 
with hospitals in general, seniors with a cognitive ability issue may find it difficult to go to such a hospital.

Thus this research aims to analyze hierarchy of quantitative plane structure at outpatient departments of senior care hospitals, which will be utilized for establishing baseline data for designing an efficient senior care hospital.

\subsection{Method and Scope of the Study}

This study has been conducted in the following procedure. First, for quantitative analysis based on plane structure of senior care hospitals, division into unit spaces has been made, which is based on the convex concept. Secondly, the J-Graph has been drawn for analysis of flow connection and space depth per unit space.Third, quantitative analysis and baseline data for design have been established through calculation of accessibility, usability and awareness on the unit space as well as space syntax analysis based on the drawn J-Graph. Location of the senior hospitals covered in this study is limited to Korea, where a high ratio of aging is found due to the surge of the aging population, and such hospitals have been selected as the ones with capacity bigger than 100 beds.

\section{Elderly Characteristic and Spatial Configuration of Geriatrics Hospital}

\subsection{Elderly Characteristic}

This study reviewed the characteristics of seniors in terms of spatial aspects, such as physical, psychological and cognitive characteristics. Details of this analysis include: 1) Physical characteristic of seniors is one of the most representative features of aging and causes weakening of mobility and vision. 2) Representative psychological characteristics of seniors include weakened memory and learning capability, which can impress upon seniors psychological adverse effects and obstacles when they go to an unfamiliar space. 3) Cognitive ability and characteristic of seniors are more limited than those of ordinary people, which can cause difficulties with using spaces with complex information, thus requiring consideration in spatial research for seniors [3].

\subsection{Spatial Configuration of Geriatrics Hospital}

Senior care hospitals are defined as the facility that provides medical service mostly to senior citizens, and are operated for those requiring treatment or nursing for senile disorders, or the patients facing immediate passing. Thus such hospitals can be determined to be the hybrid of nursing facilities and hospitals in general for treatment.

Special structures of senior hospitals include outpatient department, central treatment department, ward, checkup department, administration, supplies and funeral department, and as aforementioned, this study is limited to outpatient departments that directly deal with visiting patients. An outpatient department generally consists of the doctor's office, emergency treatment team, day care center and common space [4].

\section{Analysis of Space Hierarchy}

This study utilized the J-Graph and space syntax for quantitative space hierarchy analysis on the outpatient department, and the considerations for the analysis are as following: 


\subsection{Concept and Type of J-Graph}

J-Graph is a type of diagram which visually systemizes structural hierarchy of flow of spaces through unit spaces (nodes) and the lines (link) that connects the unit spaces. Convex is the base of the unit spaces, and this means an open space with no obstacle that the person therein can visually recognize all points in the space. Table 1 shows the process of drawing the J-Graph, and the following have been additionally applied to divide the unit space: 1) Space with the same characteristics except corridor has been considered as a single convex space even though it may be shaped with a physical angle (like L). 2) Supplies and administration departments are not directly accessed by seniors in most cases, but they have been included in the division of the convex space in consideration of ease of support [5].

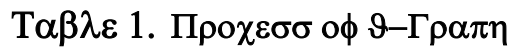

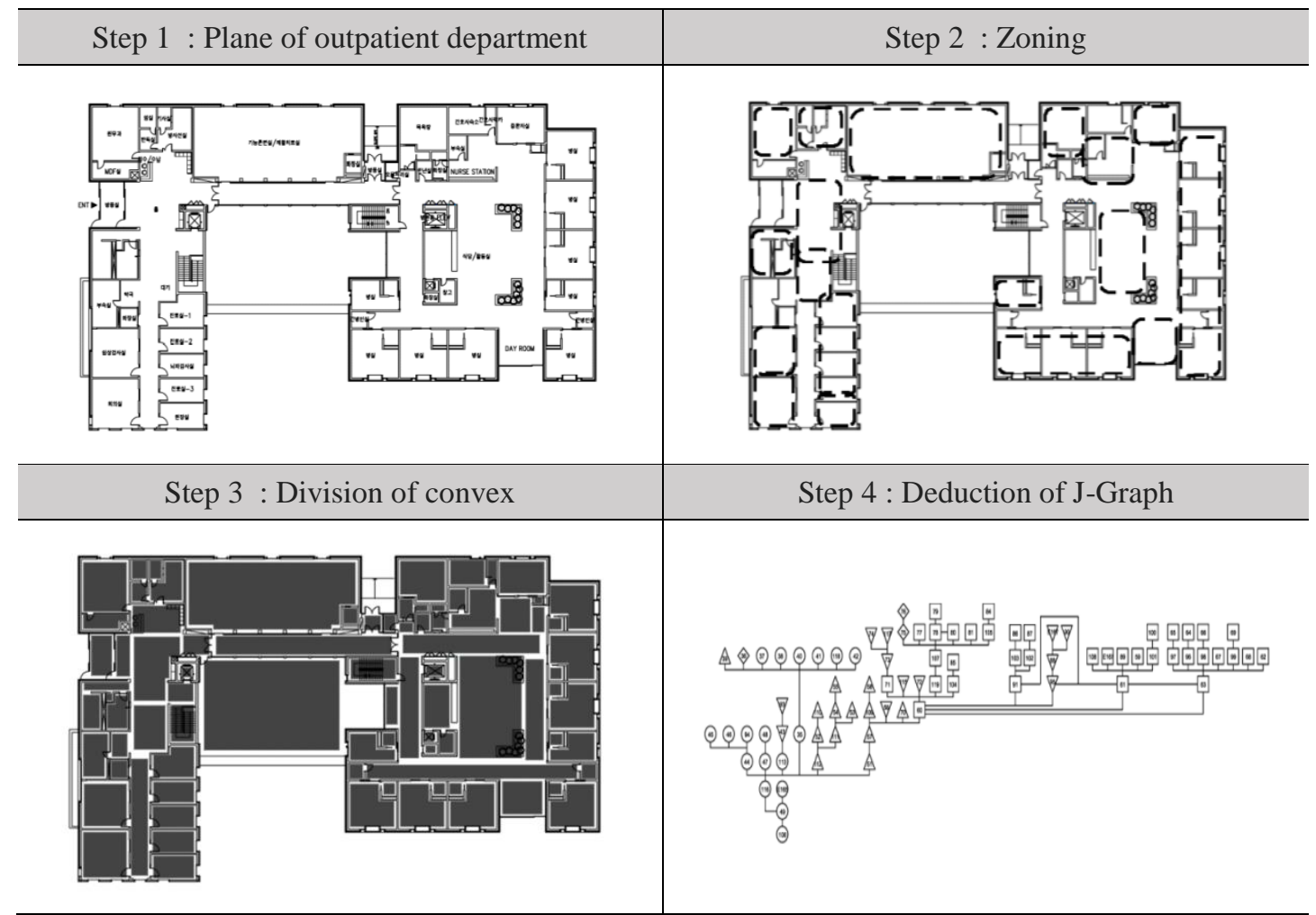

As shown in Table 2, the J-Graph is categorized into tree and ring types, the former of which is a sequential structure with hierarchical and continued properties, with higher visibility rather than permeability of the space. The ring type space shows social characteristics, and permeability takes priority to visibility thanks to highly autonomic spatial structure [6].

T $\alpha \beta \lambda \varepsilon 2$. Т $\psi \pi \varepsilon$ оф $\vartheta-Г \rho \alpha \pi \eta$

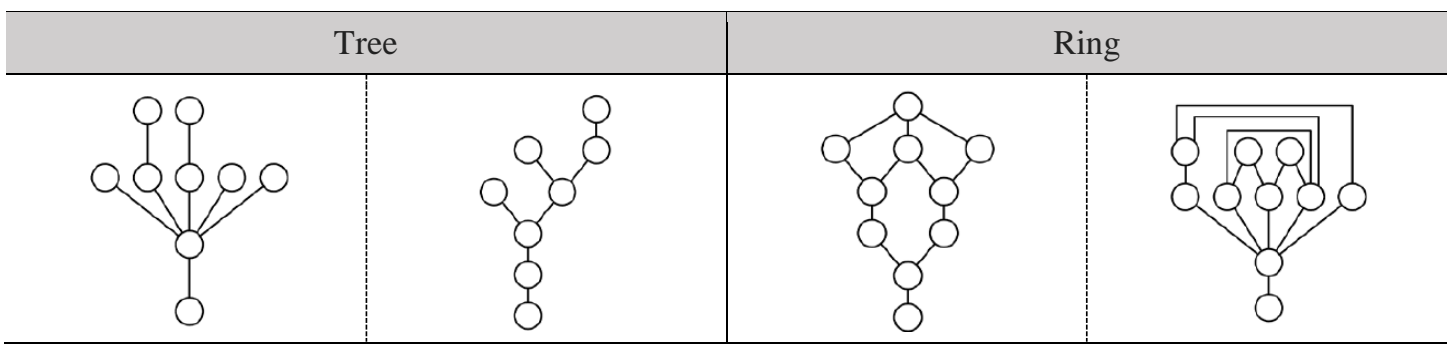




\subsection{Concept and Index of Space Syntax}

Space Syntax is a method for analyzing arrangement and hierarchy of spaces, and considers convex space as the unit space for quantitative analysis of connection of each unit space [7]. Table 3 shows major indices related with this study and their characteristics.

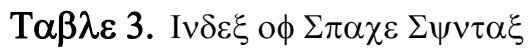

\begin{tabular}{|c|c|}
\hline Index & Concept and characteristic \\
\hline Connectivity & $\begin{array}{l}\text { The Connectivity level means the number of axes that connect a specific } \\
\text { space to surrounding unit spaces, and the space with a space with high } \\
\text { connection level shows local characteristics as it is either frequently used or } \\
\text { located at the center of the whole traffic flow. }\end{array}$ \\
\hline Integration & $\begin{array}{l}\text { Whole integration level is the index for relative depth for access to } \\
\text { surrounding spaces from a specific unit space. The higher it is, the easier it is } \\
\text { to access other areas. If control level shows local relation of a specific unit } \\
\text { space and neighboring unit spaces, whole integration represents the relation } \\
\text { of a specific space with the whole space. }\end{array}$ \\
\hline Local Integration & $\begin{array}{l}\text { While whole integration level means the arrangement of overall spaces, local } \\
\text { integration shows level of integration within adjacent range including a few } \\
\text { spatial depths. Usually up to } 3 \text { depths are considered when a person } \\
\text { recognizes a space, but the number may vary per characteristics or situation } \\
\text { of the study subject. The higher the local integration is, the higher the } \\
\text { awareness is on the space. }\end{array}$ \\
\hline Intelligibility & $\begin{array}{l}\text { The intelligibility means the correlation between the integration which } \\
\text { indicates overall attribute of spatial structure and the connectivity which } \\
\text { indicates the local spatial attribute, and if the correlation between two } \\
\text { indicators is high, the intelligibility becomes higher. If the intelligibility is } \\
\text { high, the permeability on the whole space becomes higher and the spatial } \\
\text { structure and use pattern are systematic so that the degree of understanding } \\
\text { and prediction rate on the space use become higher. }\end{array}$ \\
\hline
\end{tabular}

\section{Analysis of Hierarchy According to the Spatial Configuration}

\subsection{Selection of Geriatrics Hospital for Hierarchical Analysis}

As previously mentioned, coverage of this study has been limited to the senior hospitals in Korea where diverse researches are conducted on the recent surge of seniors, and selection of subject hospitals has been made by categorizing these into the tree and ring types of J-Graph. The resultant subjects are selected based on the related studies [1, $8,9,10,11,12,13]$, the year when the hospital opened and its size. The tree type group includes Pyeongtaek Geriatric Hospital and Tongyeong Sanitorium Hospital, while the ring type group includes Bobath Memorial Hospital and Seoul Bukbu Geriatric Hospital. Table 4 shows a description of the subject hospitals. 


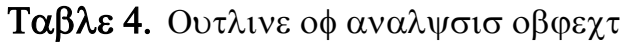

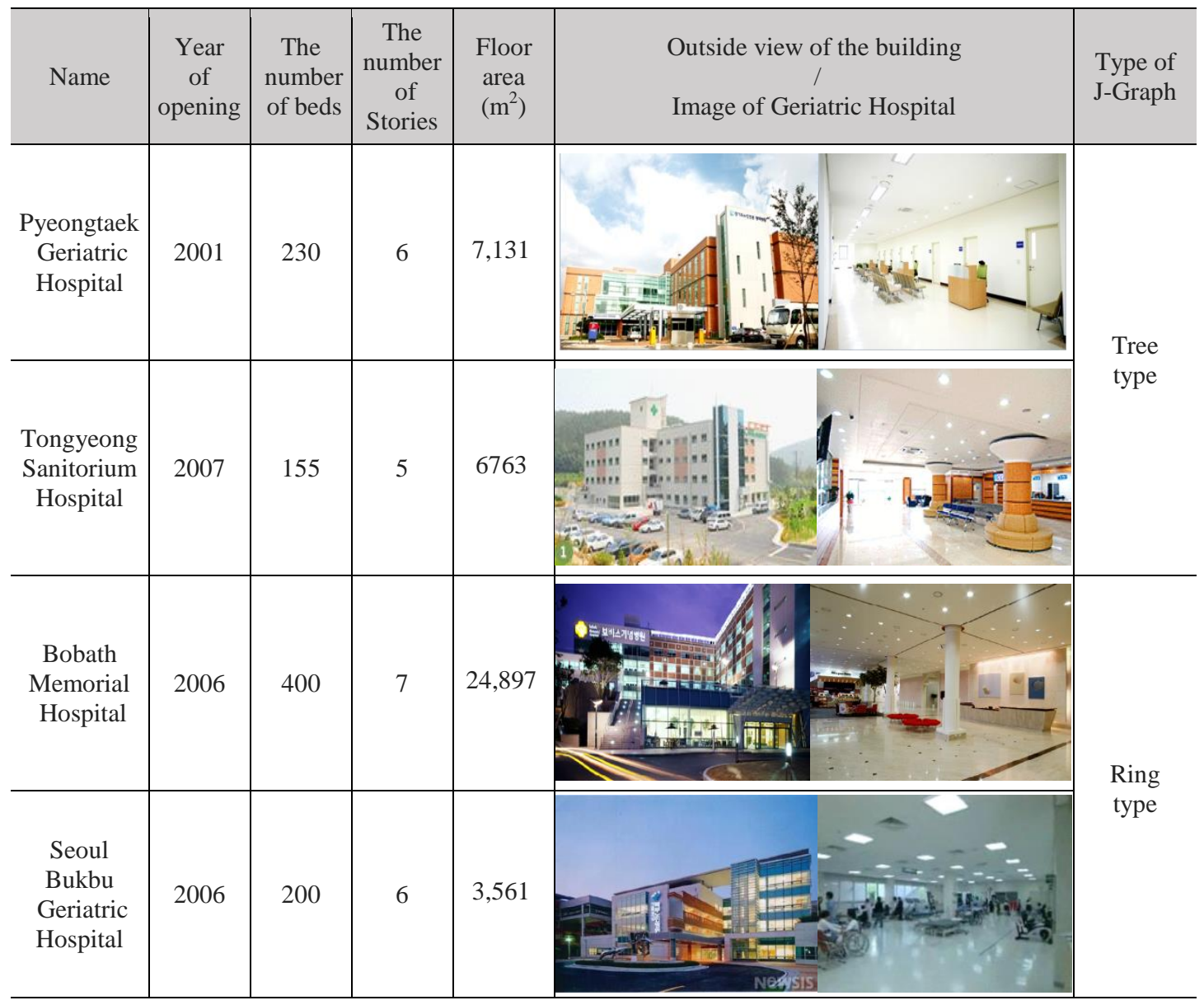

\subsection{Analysis and Deduction of J-Graph}

Table 5 shows the J-Graphs of selected hospitals, with the following characteristics.

1) Spatial depth of the outpatient departments of selected senior hospitals for this study turns out to be 5 7, averaging at 6.5 . The hospitals in the ring type group showed more depths than those in the tree type group.

2) The tree structure may be more suitable for seniors thanks to the linear flow hierarchy, while the ring structure may cause difficulty for seniors especially if they have poor cognitive ability as it may appear unfamiliar to them.

3) Spatial depth for the space for treatment is located at the deepest part due to the spatial hierarchy of the outpatient department, which may be inappropriate for the seniors with weakened physical and cognitive abilities. 


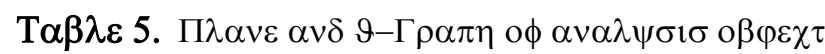

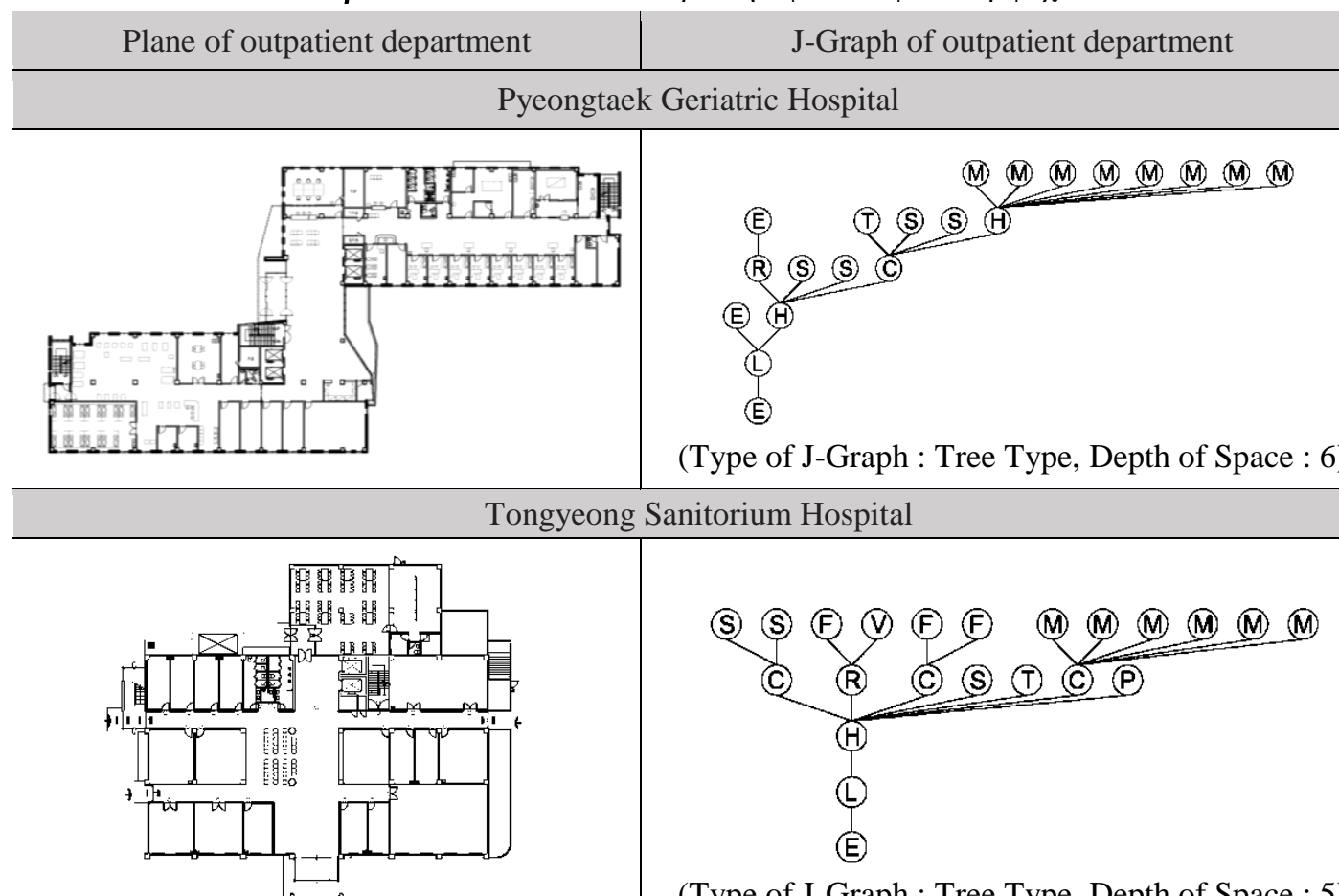

(Type of J-Graph : Tree Type, Depth of Space : 5)

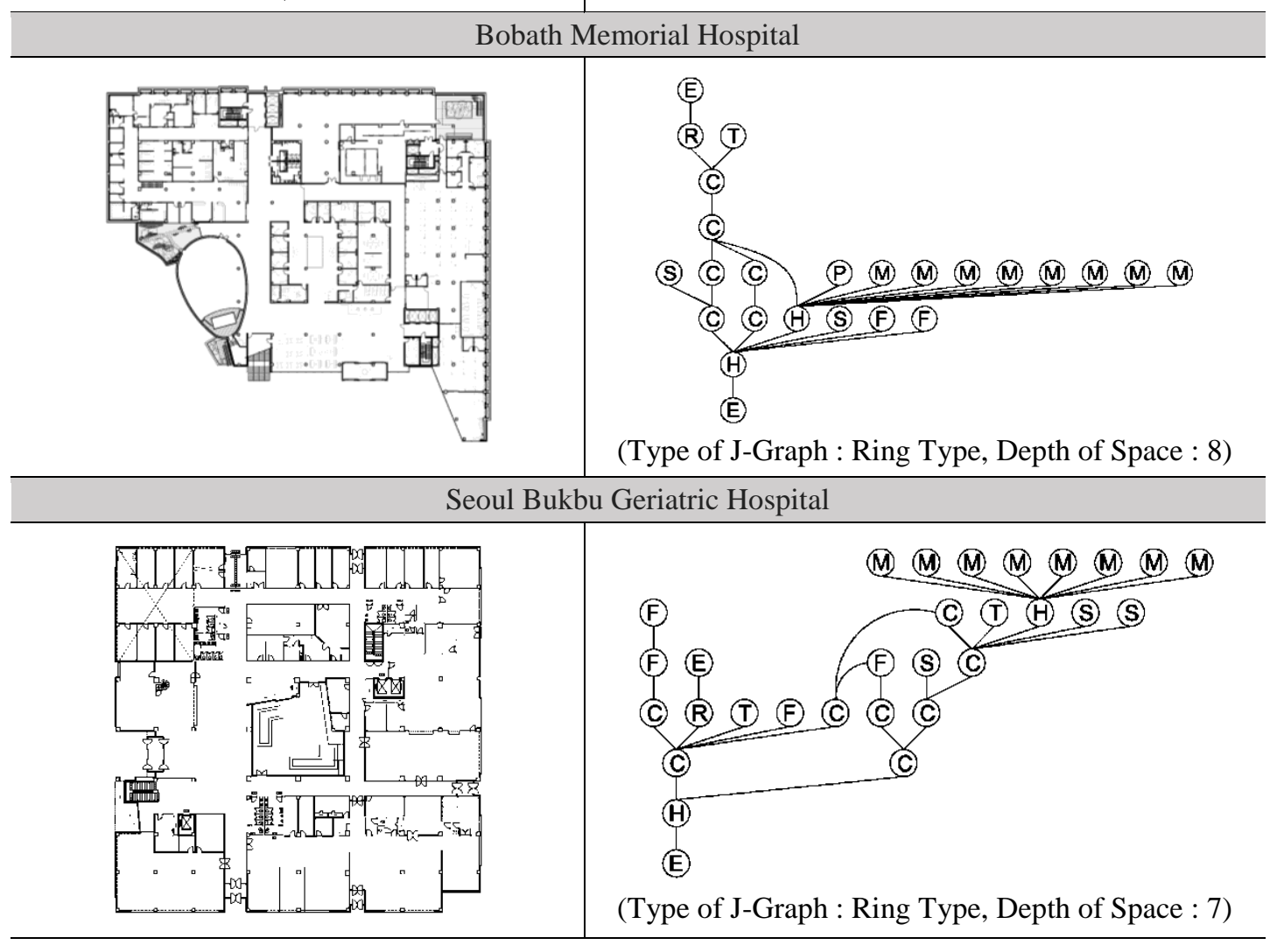

E: Entrance, C: Corridor, H: Hall, R: Elevator hall, V: Elevator, L: Lobby, T: Toilet P: Pharmacy, M: Medical treatment department, F: Convenient facilities, S: Supporting facility 


\subsection{Space Hierarchy According to the Space Syntax}

Table 6, 7 and 8 shows the analysis indices for space syntax, with results as following:

1) Outpatient departments with tree structure has high integration level and convex connectivity, which stand for the flow of patient traffic, making it easier to secure space accessibility and awareness on the department.

2) Outpatient departments with ring structure has lower values of convex connectivity and integration except the corridor for receipt of patients, resulting in poorer spatial awareness. However, it turned out to have high spatial awareness with common spaces such as shared facility or central garden, making it more appropriate for ease of sociability.

3) Calculation of intelligibility for the subject hospitals of this study resulted in the average of $35.8 \%$ for tree structured outpatient departments, which is higher than those with ring structure, thus it can be determined that the tree structure would be appropriate to design the outpatient department of senior hospitals.

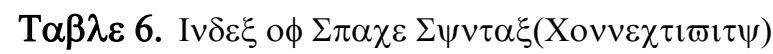

\begin{tabular}{|c|c|}
\hline Name & Index Value (These 5 only are indicated as the standard high price) \\
\hline $\begin{array}{c}\text { Pyeongtaek Geriatric } \\
\text { Hospital }\end{array}$ & $\begin{array}{l}\text { Main waiting hall of Outpatient Department (9) } \\
\text { Auxiliary waiting hall of Outpatient Department (5) } \\
\text { Lobby hall (5) } \\
\text { Corridor of reception } \operatorname{desk}(3) \\
\text { Elevator hall (2) }\end{array}$ \\
\hline $\begin{array}{c}\text { Tongyeong Sanitorium } \\
\text { Hospital }\end{array}$ & $\begin{array}{l}\text { Waiting hall (8) } \\
\text { Main waiting corridor of Outpatient Department ( } 7 \text { ) } \\
\text { Elevator hall (3) } \\
\text { Corridor of office (3) } \\
\text { Pharmacy of office (3) }\end{array}$ \\
\hline Bobath Memorial Hospital & $\begin{array}{l}\text { Waiting hall of Outpatient Department (11) } \\
\text { Main hall ( } 7 \text { ) } \\
\text { Corridor between toilet and waiting hall (4) } \\
\text { Corridor of Toilet (3) } \\
\text { Corridor on the right side of the auditorium (3) }\end{array}$ \\
\hline $\begin{array}{c}\text { Seoul Bukbu Geriatric } \\
\text { Hospital }\end{array}$ & $\begin{array}{l}\text { Waiting hall of Outpatient Department (9) } \\
\text { Corridor of reception desk(6) } \\
\text { Corridor of casualty department (6) } \\
\text { Elevator hall ( } 3 \text { ) } \\
\text { Corridor between toilet and courtyard (3) }\end{array}$ \\
\hline
\end{tabular}

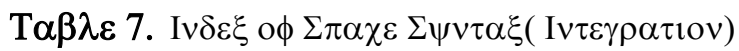

\begin{tabular}{|c|c|}
\hline Name & Index Value (These 5 only are indicated as the standard high price) \\
\hline $\begin{array}{c}\text { Pyeongtaek Geriatric } \\
\text { Hospital }\end{array}$ & $\begin{array}{l}\text { Main waiting hall of Outpatient Department (2.317) } \\
\text { Auxiliary waiting hall of Outpatient Department (1.986) } \\
\text { lobby hall (1.813) } \\
\text { Toilet }(1.127) \\
\text { Shotroom }(1.127)\end{array}$ \\
\hline $\begin{array}{c}\text { Tongyeong Sanitorium } \\
\text { Hospital }\end{array}$ & $\begin{array}{l}\text { Waiting hall }(4.642) \\
\text { Main waiting corridor of Outpatient Department }(6.125) \\
\text { Elevator hall }(2.125) \\
\text { Corridor of office }(2.125)\end{array}$ \\
\hline
\end{tabular}




\begin{tabular}{c|l}
\hline & Pharmacy of office (2.125) \\
\hline \multirow{3}{*}{ Bobath Memorial Hospital } & Waiting hall of Outpatient Department (3.069) \\
Main hall (4.924) & Corridor of Toilet (1.750) \\
Corridor on the right side of the auditorium (1.642) & Corridor between toilet and waiting hall (1.424) \\
\hline \multirow{3}{*}{ Seoul Bukbu Geriatric } & Waiting hall of Outpatient Department (8.166) \\
Hospital & Corridor of casualty department (3.944) \\
& Corridor of reception desk(3.666) \\
& Elevator hall (1.500) \\
& Corridor between toilet and nurse station (1.500) \\
\hline
\end{tabular}

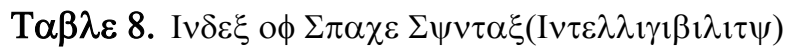

\begin{tabular}{c|c|c|c|c|}
\hline \multicolumn{2}{c|}{ Type of J-Graph : Tree Type } & \multicolumn{2}{c}{ Type of J-Graph : Ring Type } \\
\hline $\begin{array}{c}\text { Pyeongtaek Geriatric } \\
\text { Hospital }\end{array}$ & $\begin{array}{c}\text { Tongyeong } \\
\text { Sanitorium Hospital }\end{array}$ & $\begin{array}{c}\text { Bobath Memorial } \\
\text { Hospital }\end{array}$ & $\begin{array}{c}\text { Seoul Bukbu Geriatric } \\
\text { Hospital }\end{array}$ \\
\hline & $\cdot$ \\
\hline
\end{tabular}

\section{Conclusion}

This study aims to serve as the basis for foundation of baseline reference for designing senior hospitals though quantitative analysis on outpatient departments of existing senior hospitals, resulting in the following conclusions:

1) Spatial depth of outpatient department of selected senior hospitals for this study turns out to be 5 7, averaging at 6.5. The hospitals in the ring type group had the tendency of more depths than those in the tree type group.

2) Spatial depth for the space for treatment is located at the deepest part due to the spatial hierarchy of the outpatient department, which may be inappropriate for the seniors with weakened physical and cognitive abilities.

3) Outpatient departments with tree structure has high integration level and convex connectivity, which stand for the flow of patient traffic, making it easier to secure space accessibility and awareness on the department.

4) Outpatient departments with ring structure has lower values of convex connectivity and integration except the corridor for receipt of patients, resulting in poorer spatial awareness. However, it turned out to have high spatial awareness with common spaces, making it more appropriate for ease of sociability.

5) Calculation of intelligibility for the subject hospitals of this study resulted in the average of $35.8 \%$ for tree structured outpatient departments, which is higher than those with ring structure, thus it can be determined that the tree structure would be appropriate to design the outpatient department of senior hospitals. 


\section{References}

[1] H. W. Lee and S. T. Kim, "A Study on the Hierarchy in Spatial Configuration of Geriatrics Hospital”, Journal of Korea Institution of Interior Design, vol. 18 no. 5, (2009).

[2] S. J. Kwon, "A Study on the Hierarchical Space Organization of Elderly Care Facilities", Journal of Korea Institution of Interior Design, no. 34, (2002).

[3] H. U. Kim, I. H. Lee, "A Study on the Facility Program of Welfare Facility for the Old", The Regional Association of Architectural Institute of Korea Conference, vol.26, (2007).

[4] H. J. Lee, J. S. Park, "A Study of the Spatial Composition and Departmental Area Distribution in Geriatric Hospital", Journal of the Korea Institute of Healthcare Architecture, vol. 11, no. 3, (2005).

[5] J. K. Park, C. O. Oh, "A Study on the Hierarchy and Relationship in Spatial Configuration of Nursing Homes for the Elderly", Journal of Korea Institution of Interior Design, vol. 20, no. 3, (2011).

[6] S. W. Jung, "Concepts and Characteristics of Threshold Space in Korean Traditional Residential Space ; Focus on Space Constitution of Residential Construction in the Choson Dynasty Period, Journal of Architectural Institute of Korea, vol. 23, no. 7, (2007).

[7] Y. H. Cho, "The Space Characteristics of Dementia Units by Using Space Syntax Theory", Journal of Architectural Institute of Korea, vol. 26, no. 7, (2010).

[8] S.H. Kim, J.H. Lee and K.H. Kang, "Architectural planning of Geriatric Hospitals - Focused on analyzing the spatial organization and size of major areas", Journal of Korea Institution of Interior Design, no. 36, (2003).

[9] S. H. Yoon and S. T. Kim, "A Study on the Spatial Structure Change of Elderly Care Facility according to Introduction of Long-Term Care Insurance", Journal of the Korea Institute of Healthcare Architecture, vol. 20, no. 4, (2014).

[10] S. H. Kim, J. H. Lee and K. H. Kang, "Architectural planning of Geriatric Hospitals - Focused on analyzing the spatial organization and size of major areas", Korean Institute of Interior Design Journal, no. $36, \mathbf{( 2 0 0 3 )}$.

[11] M. S. Lee and H. W. Jeon, "A Study on the Characteristics of Rehabilitation for Space Configuration in the Special Clinic for the Elderly", Korean Institute of Interior Design Journal, vol. 17, no. 1, (2008).

[12] H. W. Lee, J. H. Seo, Y. S. Kim, "A Preliminary Study on the space hierarchy according to the Plan composition in Outpatient Department of Geriatrics Hospital", Advanced Science and Technology Letters, vol.100, (2015).

[13] S. M. Bae, S. T. Kim, "A Study on the Spatial Structure and Human Traffic Efficiency Geriatric Hospital”, Journal of Korea Institution of Interior Design Conference, vol. 16, no. 2, (2014).

\section{Authors}

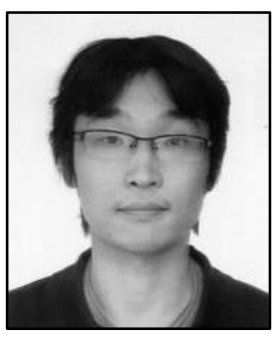

\section{Heangwoo Lee}

Research Professor, The Graduate School of Techno Design, Kookmin University

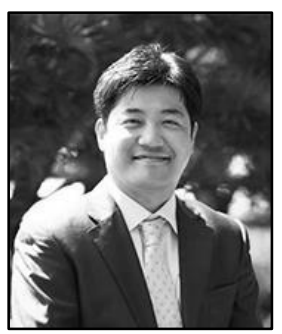

\section{Janghoo Seo}

Associate Professor, The Graduate School of Techno Design, Kookmin University

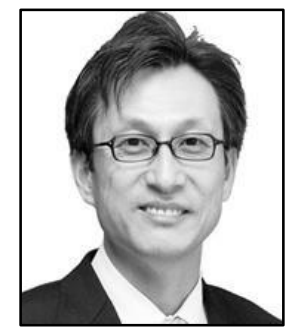

\section{Yongseong Kim (Corresponding Author)}

Professor, The Graduate School of Techno Design,

Kookmin University 
International Journal of Smart Home

Vol. 9, No. 11, (2015) 